\title{
Financiamento da extensão universitária: contribuição do Edital FAPERJ/EXTPESQ - 2010 aos projetos de extensão da UERJ
}

\section{"De que forma o financiamento con- cedido pela FAPERJ ao seu projeto de extensão contribuiu para o aprimora- mento ou expansão das ações desen- volvidas e para a ampliação do seu impacto social e/ou científico?"}

"O incentivo concedido pela FAPERJ ao projeto Comunicação e consumo urbano: ressignificando o uso e o descarte de resíduos, permitiu o planejamento de uma pesquisa de opinião e viabilizará a implementação de ações para a conscientização sobre a responsabilidade de todos os indivíduos na gestão de resíduos sólidos provindos do consumo urbano, ressignificando a representação do lixo na sociedade urbana contemporânea. Acreditamos que tais ações irão contribuir para minimizar os efeitos do lixo na qualidade de vida dos habitantes do estado do Rio de Janeiro, aumentando o nível de informação e de conscientização ambiental dos cidadãos. Os recursos oferecidos permitiram a realização da pesquisa de campo no estado do Rio de Janeiro e a montagem de um laboratório multimídia. Este espaço permitirá o desenvolvimento de canais de comunicação interativos e frequentes sobre a temática da gestão de resíduos, com base nas informações coletadas no diagnóstico, funcionando como uma ferramenta de apoio à atividade de educação ambiental." Prof. Ricardo Ferreira Freitas. FCS/UERJ.

"Diferentemente da pesquisa, a extensão universitária possui menos canais de financiamento de seus projetos e, por isso, muitas vezes caminha mais lentamente do que se gostaria. No caso do projeto de Qualificação das ações de alimentação e
No número 13 da revista Interagir publicamos uma entrevista com o Prof. Ruy Garcia Marques, Presidente da Fundação Carlos Chagas Filho de Amparo à Pesquisa do Estado do Rio de Janeiro - FAPERJ, sobre o papel dessa instituição no financiamento da Extensão Universitária.

Neste número, convidamos os 14 professores da UERJ, com projetos de extensão ativos em 2011, e que receberam financiamento para os seus projetos através do Edital FAPERJ N. ${ }^{\circ}$ 05/2010 - PROGRAMA DE APOIO A PROJETOS DE EXTENSÃO E PESQUISA - EXTPESQ - 2010, a darem os seus depoimentos sobre a importância desse financiamento para o desenvolvimento dos seus projetos.

Apresentamos nesta seção as respostas dos professores Ricardo Ferreira Freitas, da Faculdade de Comunicação Social; Inês Rugani Ribeiro de Castro, do Instituto de Nutrição; Thereza Cristina de Almeida Rosso, da Sub-Reitoria de Extensão e Cultura; Vanessa Christina Breia, da Faculdade de Formação de Professores de São Gonçalo; Heloisa Helena Ferraz Ayres, do Instituto de Psicologia; Regina Lanzillotti, do Instituto de Matemática e Estatística e Jorge Luiz Cruz, do Instituto de Artes. 
nutrição na rede pública de ensino básico dos municípios do Estado do Rio de Janeiro, o financiamento concedido pela FAPERJ possibilitou a execução de atividades cotidianas mais articuladas e abrangentes junto a seu público de interesse (municípios do estado do Rio de Janeiro) e possibilitou a ampliação do diálogo e a interação com outras instituições envolvidas nesse processo. Cabe esclarecer que, conforme previsto no projeto, o financiamento tem apoiado o desenvolvimento de projetos de pesquisa envolvendo alunos de graduação e pós-graduação do INU/UERJ. Desta forma, a extensão universitária se reafirma como processo acadêmico indispensável na formação do aluno, na qualificação do professor e no intercâmbio com a sociedade." Profa. Inês Rugani Ribeiro de Castro. INU/UERJ.

"O Ecomuseu Ilha Grande - Unidade Museu do Meio Ambiente tem por objetivo adequar as instalações do prédio mais antigo da região da Vila Dois Rios - Ilha Grande, RJ como uma edificação ambientalmente adequada. Servirá ainda de elo entre as pesquisas e ações realizadas pela UERJ e demais instituições com a população local e turistas visitantes. Nesse sentido, promove atividades que visam à preservação e valorização do ecossistema local. Os recursos financeiros aprovados pela FAPERJ para o Projeto Museu do Meio Ambiente: Ações para o saneamento ambiental têm sido fundamentais para tais realizações. Um bom exemplo foi o concurso de fotografias, aberto a toda a comunidade, realizado em Comemoração ao Dia Mundial da Água - 22 de Março - como forma de sensibilizar a população local e visitantes sobre a importância da preservação dos ambientes aquáticos para a manutenção da qualidade de vida na região. Com premiação ocorrida em 5 de Junho - Dia Mundial do Meio Ambiente - contou com a participação de candidatos da própria comunidade da Ilha Grande, como de outros estados brasileiros: São Paulo e Alagoas." Profa. Thereza Cristina de Almeida Rosso. SR-3/UERJ.

"O projeto Atendimento precoce em Equoterapia para Crianças com Encefalopatia Crônica da Infância envolve 16 crianças de 16 a 34 meses de idade, que apresentam Paralisia Cerebral. Embora a Equoterapia seja uma forma de reabilitação reconhecida pelo Conselho Federal de Medicina através do parecer 06/97, recomendada pelo Ministério da Saúde e prevista para integrar os serviços do SUS ainda não temos qualquer notificação de um serviço de Equoterapia exclusivamente público no Brasil. O financiamento da FAPERJ ao referido projeto assegura atendimento gratuito para crianças de baixa renda e nos possibilita a realização de pesquisa em uma área ainda carente de investigações. A iniciativa da FAPERJ em apoiar o projeto representa um marco não apenas para as crianças e familiares que integram o projeto, mas o reconhecimento da Equoterapia enquanto uma forma de intervenção que necessita de investimentos financeiros e técnicos, não apenas por ser promissora no que se refere à reabilitação e inclusão social de pessoas com necessidades especiais, mas também pela necessidade de qualificação de profissionais de diversas áreas que sejam comprometidos com uma prática efetivamente interdisciplinar." Profa. Vanessa Christina Breia. FFP/UERJ.

"O apoio da Faperj, através do Edital E_05 EXTPESQ, ao Projeto de Extensão Psicologia do Trabalho e Organizacional - ênfase nos processos organizacionais: Orientação ao funcionamento da Empresa Junior, do Instituto de Psicologia, vem propiciando a construção de um ambiente produtivo por meio da provisão de infraestrutura básica e de qualificação técnico-científica, viabilizando o acesso dos estudantes de graduação à inovação tecnológica, a condições ideais de aprendizagem e, portanto, a uma formação compatível com as exigências do mercado de trabalho e a consolidação das atividades de ensino, pesquisa e extensão. A importância desse apoio deve ser destacada não só pelos recursos financeiros, mas também pela credencial da Faperj, que ao aprovar o Projeto, o chancela e valoriza suas dimensões formativa e social, que indissociáveis, ligam a academia à sociedade. As parcerias da InterAção Jr/Projeto de Extensão com as incubadoras da UERJ - Empresas do Sul Fluminense (Campus Resende) e a Origem Incubadora de Empresas Inovadoras (Campus Nova Friburgo) - são um exemplo da concretização dessas dimensões; caracterizando-se pela integração entre empresários juniores, incubadoras e empreendedores, em um processo de aprendizagem e de fortalecimento da pesquisa de práticas inovadoras em gestão de pessoas. Nesse sentido, com a aprovação do Projeto pela 
Faperj, os estudantes têm ampliadas as oportunidades de pesquisa e aplicação prática de seus conhecimentos, obtendo uma formação mais sólida, fundamental para a facilitação de sua inserção no mercado de trabalho." Profa. Heloisa Helena Ferraz Ayres. PSI/UERJ.

"O projeto SEJ/IME/UERJ - Solução Estatística Junior com financiamento FAPERJ (Edital 05/2010 EXTPESQ) - Estatística como uma ferramenta de apoio à sociedade, tem gerado impacto social, pois promove o relacionamento interpessoal e tem obtido o reconhecimento dos parceiros (órgãos públicos e privados, organizações não governamentais e Instituições de Ensino Superior) pela qualidade do trabalho desenvolvido. O projeto sensibiliza os ingressantes, futuros bolsistas e colaboradores graduados, a se integrar às ações multiplicadoras, diferencial não só na inserção no mercado de trabalho como no ingresso na pós-graduação. Os estudantes têm se agregado ao projeto, pois percebem a interação entre o Ensino e a Extensão, caracterizando a experiência que viabiliza a flexibilização curricular e a indissociabilidade com a Pesquisa. $\mathrm{O}$ método tem mostrado que a tecnologia social no ambiente acadêmico, com realização simples e de baixo custo, proporcionada pelo recurso concedido pela FAPERJ, viabiliza o atendimento às demandas intra e extra UERJ." Profa. Regina Lanzillotti. IME/UERJ

"No âmbito do projeto de extensão Laboratório de Cinema e Vídeo (LCV-Art/Uerj), hoje Programa de Extensão, com os recursos do edital Proext Cultura 2008, realizamos a performance artística intitulada Máquina-performance e a documentamos em vídeo/DVD. Propusemos então aprofundar algumas questões com o Máquina-performance 2: o desfile, através da qual retomaremos a discussão sobre a realização da performance, a sua documentação e distribuição, com uma poética documental que permita fomentar o debate sobre as práticas e teorias audiovisuais contemporâneas. Através do Edital Ext/Pesq, de 2010, a Faperj reconheceu e valorizou a natureza extensionista da nossa proposta, como o processo cultural, científico e educativo que articula a pesquisa e o ensino de forma indissociável e viabiliza a relação transformadora entre e universidade e a sociedade que, assim, pretende integrar a ação artística e a formação acadêmica." Jorge Luiz Cruz. IART/UERJ 
